DR RUTH ELLIOTT (Orcid ID : 0000-0002-1364-1072)

Article type : Original Article

\title{
Mental health nurses' understandings and experiences of providing care for the spiritual needs of service users: a qualitative study.
}

\section{(running title: Mental health nurses and spiritual care)}

\author{
Authors - \\ Dr Ruth Elliott \\ Senior Lecturer MH Nursing \\ School of Human and Health Science \\ University of Huddersfield
}

Email: r.h.elliott@hud.ac.uk Tel: 01484471999

Prof. John Wattis

Visiting Professor

School of Human and Health Sciences

University of Huddersfield

Dr Kathleen Chirema

Retired Principal Lecturer

School of Human and Health Sciences

University of Huddersfield

This article has been accepted for publication and undergone full peer review but has not been through the copyediting, typesetting, pagination and proofreading process, which may lead to differences between this version and the Version of Record. Please cite this article as doi: $10.1111 /$ jpm. 12560

This article is protected by copyright. All rights reserved. 
Dr Joanna Brooks

Lecturer

Manchester Centre for Health Psychology, Division of Psychology and Mental Health, University of Manchester

Acknowledgements: Prof Felicity Astin who acted as a critical friend.

\section{Ethical statement:}

Research ethical approval for the study was obtained from NHS Research Ethics (IRAS Project ID: 132015). Management approval from the relevant NHS Trust was also obtained.

\section{Relevance Statement:}

Mental health nurses have a professional obligation to attend to service users' spiritual needs but little is known about how nurses understand this aspect of care and deliver it in practice. The study, undertaken from the mental health nurse perspective, showed that mental health nurses experience anxieties around distinguishing spiritual need and symptoms of mental ill health and have realistic concerns about how their own beliefs affects their professional credibility. Educational experiences need to emphasise both pragmatic and empathetic approaches (identified in the study) and work needs to be organised to support good practice.

\section{Abstract}

\section{Introduction}

Mental health nurses have a professional obligation to attend to service users' spiritual needs, but little is known about specific issues related to provision of care for spiritual need faced by mental health nurses or how nurses understand this aspect of care and deliver it in practice.

This article is protected by copyright. All rights reserved. 


\section{Aim/Question}

To explore mental health nurses' understandings of spiritual need and their experiences of delivering this care for service users.

\section{Method}

A qualitative study was conducted in one NHS mental health service. Interviews were undertaken with seventeen mental health nurses practising in a variety of areas.

\section{Results}

Four themes were generated from thematic analysis of data in the template style:

Expressing personal perspectives on spirituality; Expressing perspectives on spirituality as a nursing professional; Nursing spiritually; Permeating anxiety (integrative).

\section{Discussion}

Participants had complex understandings of spiritual need and evident anxieties in relation to this area of care. Two different approaches to nursing spiritually are characterised as [i] pragmatic (concerned with procedural aspects of care) and [ii] spiritually empathetic. Mental health nurses were uncertain about the acceptability of attention to spiritual issues as part of care and anxious about distinguishing between symptoms of mental ill health and spiritual needs.

\section{Implications for Practice}

Educational experiences need to emphasise both pragmatic and empathetic approaches and work needs to be organised to support good practice.

\section{Accessible Summary}

What is known on the subject

Addressing spiritual issues to maintain a sense of hope, meaning and purpose can be an important aspect of mental health care which goes beyond simply providing facilities for religious observance. Expressions of spiritual need from service users can potentially be confused with symptoms of mental ill health. Little is known about how mental health nurses understand or provide this aspect of care for service users.

This article is protected by copyright. All rights reserved. 
What the paper adds to existing knowledge

- An understanding from the mental health nurse perspective of how of mental health nurses understand and care for service users' spiritual needs, and what influences their practice in this area

- Ideas about how education and opportunities for good practice in this area might be advanced.

What are the implications for practice

Nurses need more education and guidance as well as supportive team and management cultures so that they feel comfortable and able to deliver this important aspect of care.

\section{Relevance Statement:}

Mental health nurses have a professional obligation to attend to service users' spiritual needs but little is known about how nurses understand this aspect of care and deliver it in practice. The study, undertaken from the mental health nurse perspective, showed that mental health nurses experience anxieties around distinguishing spiritual need and symptoms of mental ill health and have realistic concerns about how their own beliefs affects their professional credibility. Educational experiences need to emphasise both pragmatic and empathetic approaches (identified in the study) and work needs to be organised to support good practice.

\section{Background}

In recent decades, there has been increasing literature recognising the importance of spirituality in the context of mental health care (Narayanasamy, 1999; Pesut, 2008; McSherry \& Jamieson, 2011; Rogers \& Wattis, 2014; Weber \& Pargament, 2014). Whilst there is no clear agreed definition of 'spirituality' in the health and social care literature (Bregman, 2014), Swinton and Pattinson (2010) have argued for a "thin, vague and useful understanding of spirituality" in clinical practice. Nurses have a professional obligation to care for patients holistically and, according to regulatory body standards for nursing in the United Kingdom (UK) it is part of a nurse's role to assess and address service users' spiritual needs (Nursing and Midwifery Council, 2014). Mental health nurses therefore need to have the skills and professional competencies to effectively and safely include spirituality in their nursing practice. (McSherry, 2011; NMC, 2014).

However, there is at present rather little known about how care for spiritual need is understood and undertaken in nursing practice. Whilst recognising spirituality as a fundamental aspect of nursing care, many nurses responding to a UK survey in 2010

This article is protected by copyright. All rights reserved. 
reported that they did not feel confident providing such care and felt that they needed better support and education (McSherry \& Jamieson, 2011). Spiritual care in nursing has previously been described as 'procedural' (Narayanasamy \& Owens, 2001) - when spirituality is primarily defined in simply religious terms it is relatively straightforward for a nurse to evidence how spiritual needs have been met (Swinton, 2001). The reluctance in research and education to address spirituality in a more meaningful and broader sense in nursing and mental health care may be because of a perceived lack of professional credibility around the topic, resulting in it not being treated as a significant aspect of holistic care (Swinton, 2001). Additionally, nurses working in a mental health context are likely to face other unique issues affecting person centred care. Serious mental illness may run hand in hand with diminished capacity, Mental Health Act applications, and psychotic phenomena which may distort the expression of spiritual need (Barker, 2004; Elliott, 2011). Issues specific to mental health nursing include distinguishing culturally (or sub-culturally) 'normal' spiritual experiences from phenomena (especially delusions and hallucinations) understood as symptoms of mental ill health (Mitchell \& Roberts, 2009). Mental health nurses may fear misinterpreting spiritual needs or experiences of the service users and confusing them with symptoms of mental illness, and this may cause reluctance to provide spiritual care (Barker 2004; McBrien, 2006; Swinton and Pattinson, 2010) as nurses may feel unprepared or uncomfortable in supporting spiritual need (Koslander \& Ardvidsson, 2006; Elliott, 2011). There is a paucity of research regarding specific issues related to provision of care for spiritual needs which may be faced by mental health nurses and which seeks to understand, from the mental health nurse perspective, how they provide care for service users' spiritual needs.

\begin{abstract}
Aim
The aim of this study was to explore how mental health nurses understand and care for the spiritual needs of service users.
\end{abstract}

\title{
Method
}

\section{Study design and theoretical framework}

A qualitative study adopting a limited realist stance was undertaken to facilitate an indepth understanding of the mental health nurse perspective (King and Brooks, 2017).

King and Brooks (2017, p.18) describe a limited realist stance as having "a commitment to a realist ontology combined with a constructivist epistemology. Put simply, they [those taking this stance] believe the world has a reality outside of human constructions of it, but that our understanding of it is always limited by our position within it." Our focus in this work is on personal understandings and subjective individual experience - we are concerned with what is true for participants rather than any objective truth, and we are therefore committed to a constructivist epistemology. However, the study was undertaken in a health care setting with the intention of producing findings with relevance for services in applied settings. The

This article is protected by copyright. All rights reserved. 
research is thus understood as being part of a broader existence which has a concrete reality outside of human constructions of it (King \& Brooks, 2017).

We have drawn on the criteria specified in the Consolidated Criteria for Reporting Qualitative Research (COREQ; Tong et al., 2007) to ensure rigour in our reporting of this work. Ethical approval for the study was received from the relevant local National Research Ethics Committee. Individual semi-structured interviews were undertaken with mental health nurses working in one organisation in a variety of specialist settings. Interview data were analysed using template analysis (e.g. Brooks et al, 2015), a particular style of thematic analysis. In keeping with other approaches to thematic analysis of qualitative data, template analysis is a flexible approach not tied to any particular methodology or epistemological stance. When using thematic analysis approaches, the onus is therefore on the researcher to be explicit about the stance they have adopted and to explain why this is appropriate. The limited realist stance underpinning this study is in keeping with our concern with subjective personal accounts from mental health nurses working in applied healthcare settings. This approach has been successfully used previously in healthcare research, including research with healthcare professionals (e.g. Waddington \& Fletcher, 2005; King et al, 2017). An inductive, data-driven approach to analysis was appropriate for this study as our aim was to explore and understand the mental health nurse perspective.

The study was led by the first author, currently a senior lecturer in mental health nursing at a university, and registered mental health nurse with a clinical background including twenty years of working in various mental health services. In clinical practice, the first author had many encounters with service users from diverse backgrounds who expressed spiritual needs during assessment of their mental health needs. It was her perception that if a service user expressed what she considered a spiritual need, this was often viewed by health professionals as a symptom of their illness. In her clinical work, it seemed to the first author that the use of medication and other mental health interventions were viewed as successful if the service user stopped their religious or spiritual expression. Whilst acknowledging this may be relapse signature for some, as someone who understood spirituality in her own life as supportive and useful, this was a concern to the first author. These experiences provided the impetus for and underpin the work reported here. The other members of the research team were a female lecturer in health psychology with expertise in qualitative methods and experience in health service research without any spiritual or religious special interests; a male professor of old age psychiatry with a long-term interest in spirituality in health care; a female lecturer in nursing and qualified nurse.

\section{Participant recruitment and study setting}

Participants were recruited from one mental health NHS Foundation Trust covering a large geographical area in the North of England. The Trust provides specialist inpatient and community mental health and learning disability services including medium secure care. Email invitations were sent to all clinical mental health nurses with basic information about the study and inviting participation. Inclusion criteria specified that participants should be

This article is protected by copyright. All rights reserved. 
qualified mental health nurses who had contact with service users. 22 people responded to the email invitation. One respondent did not hold a mental health nursing qualification and four other respondents expressed initial interest but did not go on to take part in the study due to limited time and availability $(\mathrm{N}=2)$ or subsequently deciding they did not wish to take part in a research interview $(\mathrm{N}=2)$. A final sample of 17 nurses participated in the study.

\section{Data collection}

Interviews were conducted in a private room at the participant's preferred location (either at the participant's or the researcher's place of work). Three key questions provided a guide to frame and structure the interviews: 'What is your understanding of spirituality and spiritual needs?'; 'How would you assess or recognise spiritual needs in service users?'; 'What would you do with this information?' Probing and prompt questions were used as appropriate to encourage elaboration, and participants were encouraged to talk openly and in detail about their own views, experiences and concerns. The interview guide was piloted with a colleague (a nurse educator).

All participants provided informed written consent before their interview. Interviews were undertaken by the first author (undertaking this work as part of a professional doctorate in nursing and with academic training at postgraduate level in undertaking qualitative research but limited experience in undertaking research interviews prior to this study). Reflective field notes were made after each interview. Interviews were digitally audio-recorded and transcribed in full. Transcripts were checked by all members of the research team but were not returned to participants. Participants were interviewed on one occasion only. Interview length varied from 36 to 86 minutes (see Table 1).

The first author had an existing relationship with some interviewees due to her previous employment in the Trust as a nurse. She had worked with three participants in her capacity as a nursing colleague several years prior to the study and knew two other colleagues by name and professional reputation. All were professional associations and were not current relationships or friendships. For those interviewees she did not previously know, email and telephone contact before the interview to arrange an appointment provided a way of establishing some relationship. All participants were aware that the interviewer had previously worked as a mental health nurse and that this work was being undertaken as part of a professional doctorate. Before the interview, all participants discussed with the interviewer her personal reasons for an interest in the research topic (these included her own experiences of working with service users to address spiritual need, and challenges faced as a nurse educator incorporating spirituality into the taught curriculum). The interviewer's own spiritual beliefs and affiliations were not raised or discussed with participants - the interviewer was concerned that over disclosure may distort the interview and this type of strategy was described by Ashmore and Banks (2002) in their research on self-disclosure in adult and mental health nursing students. Overall, though some personal disclosure and the interviewer's 'insider' status were helpful in promoting open discussion as evidenced by the rich interview

This article is protected by copyright. All rights reserved. 
data obtained. A potential drawback was participants' assumption of a shared professional understanding (for example, using facial expression or closed phrases and jargon). Rather than assume understanding, the interviewer tried to encourage participants to fully articulate their viewpoint (for example, by reminding them she had not been in clinical practice for some time and could they remind her or explain a little further). The researcher's position as a mental health nurse was an advantage in terms of establishing rapport but required that she question her own assumptions throughout. The approach taken throughout this study was in line with the view taken by Dwyer and Buckle (2009) that "the core ingredient is not insider or outsider status but an ability to be open, authentic, honest, deeply interested in the experience of one's research participants, and committed to accurately and adequately representing their experience" (p.59).

\section{Data analysis}

Data were analysed using Template Analysis (e.g. King \& Brooks, 2017). Template analysis involves the development of a coding template, which summarises themes identified in a qualitative data set through a process of coding and organises these themes hierarchically in a meaningful and useful manner (Brooks et al, 2015).

Analysis was led by the first author, and discussed and checked by the full research team. These contributions allowed for useful reflection on the data from a number of viewpoints, although participants themselves were not asked to provide feedback on the findings. We recognise that some recommend member checking as good practice, and that this may be therefore be understood as a limitation of this work. There is though debate as to whether feedback from participants necessarily enhances research credibility (Thomas, 2017) and we agree with others that participant opinions cannot not simply be understood as 'an authoritative judgement of the veracity or value of the interpretation' (Yardley, 2000, p. 221). Participants may feel uncomfortable criticising (because of perceived power imbalances or simply because they want to be helpful), and any assumption that a participant can simply examine an interpretation of some aspect of their experience and judge whether it is 'right' contradicts the assumption underlying much qualitative research that such objective assessment is not in fact possible (King \& Brooks, 2017). Throughout the research process and analysis, The lead author sought to reflect on her own perspective to provide as credible an interpretation of the results as possible. In order to further enhance credibility, analysis was continually reviewed and discussed with full research team who were not mental health nurses and who held different and varied understandings of spirituality in an effort to limit any personal bias.

Analysis was inductive and data-driven, and analysis followed King and Brooks' (2017) guidance on undertaking template analysis. Preliminary coding involved reviewing the whole data set, highlighting any segments which contributed to the research question and assigning these initial descriptive labels. These labels or codes were organised into meaningful clusters, a process which was facilitated by using sticky-notes and flip chart paper. This provided a clear visual overview and allowed for easy modification of the emerging structure. The chart was then transcribed into a word document, clusters were

This article is protected by copyright. All rights reserved. 
organised and further refined into an initial version coding template. The initial template was then applied to the data set iteratively, resulting in modifications to avoid replication and to better delineate some themes. Regular research team meetings throughout analysis assisted in appropriate reflexivity and through discussion all team members were able to reflect on their own assumptions about the research topic and ensure that analytic interpretations were grounded in the data. For each iteration of the developing template, codes and themes were discussed and clear definitions developed to ensure that the authors were explicit about decisions made and that a clear audit trail was established (see Elliott, 2017). A particular feature of Template Analysis is that the hierarchically-ordered coding template may also reflect lateral relationships across theme clusters: these integrative themes permeate and connect other themes. Our final template included four main top-level themes (each with sub-themes), and we identified one of these top-level themes as an integrative theme. The final version template and interview transcripts were uploaded onto NVivo and the final template applied to the full data set, ensuring that interpretations presented remain grounded in and evidenced by the data.

\section{Findings}

Table 1 summarises key participant characteristics and interview durations.

(Please insert here)

Four top-level themes were generated through analysis (see figure 1 for final version template showing top level themes and first level subthemes):

1. Expressing personal perspectives on spirituality

2. Expressing perspectives on spirituality as a nursing professional

3. Nursing spiritually

4. Permeating anxiety (Integrative)

(Please insert table 1 here)

\section{Expressing personal perspectives on spirituality}

This theme captured participants' personal views of spirituality, derived from their personal life rather than from their professional role as a nurse. It highlights how developing a personal understanding and meaningful definition of spirituality were described by participants in terms of a developmental task.

This article is protected by copyright. All rights reserved. 
Participants were not overtly questioned on their personal background as part of the interview, yet all participants reflected on the role this experience and history (including family, school, social life and friends) had played in developing their own understanding of spirituality. Participants perceived various influences from their past as important in developing an understanding of spirituality, and the notion of 'beginning to question' was common across participants. Even when participants described rejecting or changing their views over time, these personal historical influences had shaped participants' understandings of spirituality, and appeared to affect their professional approach towards service users and best-practice care:

'It wasn't until I became a free thinker I began to question. I wouldn't say I was force fed, err well I suppose Catholic school is a lot of pressure. That was quite difficult ...I'm very aware that it's incredibly important to people and that's what's important not what I think. I like to think that I can relate to it and l'd be lying if I didn't think that it would be a nice comfort to have in your last hours, your time of real need." [Nick]

Participants reported taking elements they found useful from important influences in their own experience to develop personal understandings of spirituality - for example, Lisa described her spiritual beliefs as "a pick and mix of everyone else's that l've grown up with". Spirituality was understood as a complex term that could be related to but was not the same as other concepts (such as compassion, empathy and religion). Although there were some features perceived by participants as key to explanations of spirituality (such as connectedness), understandings of spirituality were often very personal. Participants were often uncomfortable in the interviews about their inability to 'evidence' their talk about spirituality. The difficulties in 'finding the right word' or an adequate way of capturing their thoughts and beliefs was commented on by participants. Some commented that the word 'spirituality' was a problem (e.g. "Gets in the way cos it's a social construct and the term spirituality puts a block up" [Ben]). Spirituality then is understood as subjective, nebulous and delicate whilst also universal. This is seemingly contrasted by participants with identification with a recognised religion, described by participants as serving as a useful and socially understood label and not necessarily requiring this extensive self-reflection (e.g. "Being a Catholic and going to Catholic school, there's never any other option." [Harry]). Whilst recognising spirituality as universal to all (and important in service user care), participants could not simply define the term without drawing on their personal idiosyncratic experience and beliefs resulting in a clear sense of vulnerability. The tensions this could create in their role as a nursing professional engaged in service user care are examined in the following theme.

This article is protected by copyright. All rights reserved. 


\section{Expressing perspectives on spirituality as a nursing professional}

The previous theme looked at how participants described understanding spirituality as an individual in their own lives and how these very personal understandings developed outside their professional (mental health nursing) role. The second theme describes how participant's understanding of spirituality may be changed or influenced by their role as a nursing professional - specifically through nurse training, colleagues and professional expectations. The nurse may carry the 'spirit' of their beliefs which they have already been exposed to in their personal life but may have changed their thoughts or behaviour in relation to their professional standing and as a result of their professional standing.

In the previous theme we noted that participants were seemingly uncomfortable with their inability to 'evidence' their reflections on spirituality. Participants recognised evidence- based practice as a key tenet of nursing. This could present tensions when considering an individual service user's spiritual beliefs and needs:

"If we talk about spirituality as opposed to delusion, it's quite easy for me because l've got no great certainty, so it's easy for me to say to someone [service user], you could well be right."

[Harry]

This lack of clear-cut 'evidence' also made participants cautious about openly discussing spirituality with colleagues in their role as a nursing professional. Rachael described her concerns around being ridiculed or judged by colleagues within her team should she disclose her private thoughts around spirituality. She recounted an experience when a service user had expressed what were viewed by the nursing team as delusional beliefs but which she personally believed were spiritual phenomena.

Can you imagine reading that out in your MDT meeting? They'd look at me and refer me to the NMC or get out the pink papers" (note - MDT refers to multidisciplinary team; NMC refers to the Nursing and Midwifery Council; 'pink papers' refers to application for admission to hospital under the Mental Health Act)

[Rachael]

For some participants then, there is a split between the personal and spiritual and their professional role. How an individual experiences their team and understands their role within it is key here. Whether or not an individual feels able to express their own views

This article is protected by copyright. All rights reserved. 
seems to depend on the extent to which they feel part of their team and as part of a supportive and accepting community. Some participants discussed their teams in terms of an 'approach' or 'ethos' and how working as part of a team influenced spiritual care.

'[Speaking of a particular service user] But she is unique. Quite a serious consideration has been given to that [her unique spiritual need] and it's not unusual in this team."

[Ann]

Teams played an important role - whilst a good team seemed to be understood as taking the same approach, this could mean that individuals who did not share the common view acquiesced to an overall approach which they did not feel best supported a service user's spiritual need.

"I've watched nurses and not always agreed with the approach they've taken. For example, they seem to become resilient to people's problems and lack the empathy that is required"

[Freya]

Participants also discussed how nurse education and training had influenced their professional understandings of spirituality, usually reporting they had found education around this aspect of care to be inadequate.

I was taught in a more traditionalist manner really and it was if you saw this set of symptoms this is what you would do. It was a simpler time but a lot less dignified and negated people's spiritual needs. I think if you treat people the same I think that's the most fundamental thing against someone's spiritual need.

[Lisa]

With the advent of person-centred holistic care, there was a sense that training and education may be improving but still has some way to go.

"Are we trained to think around looking at people from a spiritual point of view? I think we have got better at it but it's definitely lacking in spirituality.

[Mary]

This article is protected by copyright. All rights reserved. 


\section{Nursing Spiritually}

The first two themes illustrated what influenced participants' understanding in relation to their personal and professional experiences. This theme concerns how mental health nurses described applying their understanding of spirituality derived (as established in the first two themes) from both personal and professional experiences, in their nursing practice and what influenced their decisions on how best to provide care for spiritual need. This theme also describes styles which influenced decisions around how best to provide care for spiritual needs.

Participants talked about 'nursing spiritually' in either what we term a pragmatic or spiritually empathetic sense - two broad styles, distinct but not necessarily mutually exclusive. Although participants did not necessarily exclusively adopt either a pragmatic or a spiritually empathetic approach, some clearly tended to favour one approach over the other. Those preferring a pragmatic approach tended to focus on very practical aspects of nursing - for example, on ways of providing a service user with opportunities to practice their religion ("It might be something like I want a priest to come [on the ward]" [Chris]). The spiritually empathetic approach was described by participants in terms of seeing the whole person in a wider context that arguably went beyond some traditional notions of holistic or personcentred care. Spiritually empathetic nurses did not always see themselves as especially 'spiritual' but displayed a sensitivity towards the service user's sense of spiritually. The sense was of going beyond what might be seen as the usual realm of care to recognise and facilitate something deeper and more profound for service users, reflected in the use of more abstract terms such as 'light in their eyes' 'light' 'spark' 'spirit' and 'spirit loss'. The spiritually empathetic approach was described by participants in terms of 'unspoken' acknowledgement and recognition of a spiritual connection with the service user.

"The spirit within me recognises the spirit within that other person. Spirit and soul I think is probably the same thing. In my head it's the same and the inner part you that you recognise in others. In service users which gives me feeling of connectedness" [Kate]

Others too reflected on spiritual care as involving a recognition of a shared humanity with service users and it is this approach we characterise as spiritually empathetic.

It's about how you connect with a person and what you value yourself as a person and what you value in others and what you value in the world. So for me it's about how do I help a person to connect with that or how do I connect with them? In terms of working with people with a mental illness, I think that is a spiritual approach"

[Ann]

This article is protected by copyright. All rights reserved. 
Participants intimated that spiritual needs were only partially addressed because of the expectations in standardised assessments, forcing nurses to take a pragmatic approach which was described as rather limited.

"It isn't about asking people what religion they are and ticking one of them sixteen boxes. Although it's tempting for someone like me who is very process driven to think it's just ticking a box but it certainly isn't."

[Lisa]

Participants also acknowledged that particular service user diagnoses were likely to significantly impact on how a service user's spiritual needs might be assessed and responded to (it was interesting that participants tended to revert to the less personal 'we' or 'they' when recounting this, rather than relating direct personal experience from the ' $\mathrm{l}$ ' perspective). Certain diagnostic labels (participants highlighted psychosis, personality disorder and schizophrenic disorders in particular) were understood as changing the understanding and meaning of spirituality and spiritual care, and service user expressed beliefs could be used instead as a proxy assessment of mental health status

"If anybody mentions a reference to spirituality it's deemed a delusion or some psychotic feature."

[Dawn]

This was contrasted with other diagnoses such as depression where it is seemingly acceptable to express spiritual beliefs without them being regarded as a symptom of illness:

"Most people can identify with depression 'cos in your life people do experience a mild form or even more severe, but a lot more people can identify with anxiety and depression than they can with psychosis. Not many people can identify with hearing voices"

[Ann]

\section{Permeating anxiety}

'Permeating anxiety' was an integrative theme indicating a typical attitude to all discussions on the topic of spirituality across the interviews and cutting across all other themes. Participants' had evident anxieties around discussing spirituality and spiritual need. Nurses understood spirituality as something to take seriously in the course of providing care and felt a real sense of responsibility. However, they were anxious of the potential to cause offence, of ridicule and embarrassment, of 'getting it wrong' or imposing their own beliefs on service users and colleagues. This often presented itself as a concern about how the researcher would perceive them and their professional competence. Prior to taking part in the interview, some participants had researched 'spirituality' (typically evidenced by comments such as "Actually, I've written some things down" or "I looked it up after I got the invitation") whilst others said they wished they had or acknowledged it as an idea:

This article is protected by copyright. All rights reserved. 
"I haven't read up about it though so I don't know if I'll give you the right answers."

[Dawn]

In the first theme (personal perspective), some participants referred to 'fear' in relation to their personal (religious) upbringing. Joe, for example, equated spirituality with existential anxiety.

"Fear, death and dying. Yeah, Extreme fear. When you are very much at risk or you're frightened of the unknown. That is when your spirituality is tested".

[Joe]

There were explicit examples of 'fear and anxiety' in the second theme - we have already drawn attention to fear of being negatively judged by colleagues and perhaps ostracised from the team which evidently plays such a key role in the lived experience of a nursing professional. Fitting in is important, and Rachael for example described how she questioned her own beliefs during her nurse training

"You start to question your own self because of your beliefs and how it fits with your training."

[Rachael]

'Anxiety' was repeatedly evident in the third theme. Fear of 'getting it wrong' featured strongly and was discussed in relation to misinterpreting spiritual phenomena as symptoms of mental ill-health. For example, some participants highlighted how spiritual and cultural expressions might be used as a 'barometer' for assessing a person's mental health presentation.

"What l'm worried about is that we give medication for that and we don't explore first"

[Emma]

\section{Discussion}

This study explored in detail, from the mental health nurse perspective, how mental health nurses understand and care for the spiritual needs of service users. The four themes presented highlight complex understandings on this topic and draw attention to the anxieties of mental health nurses in relation to this area of care. Spirituality was understood by our

This article is protected by copyright. All rights reserved. 
participants as both personal and universal. This could create apparent tensions between nurses' understanding of what constituted a safe, appropriate and professionally boundaried role on the one hand, and the perceived usefulness of drawing on their own experiences and personal understandings to facilitate this type of care on the other.

Two broad approaches to 'nursing spiritually' are described here as pragmatic and spiritually empathetic. These approaches are complementary rather than antagonistic and some interviewees consciously flexed their approach depending on the service users need and the context. The pragmatic approach focused on very practical aspects of nursing spiritually for example, on ways of providing the service user opportunities to practice their religion. Previous work has also suggested that nurses may find it easier to address 'spiritual need' simply in terms of religion (Elliott, 2011; Narayanasamy \& Owens, 2011), and this was evident in many of the mental health nurses' narratives in the present study when they described how they facilitated religious practices. Participants in this study talked about how they felt pressured at times by perceived professional expectations to adopt the pragmatic approach and they recognised this may have been a missed opportunity to fully support a service user's spiritual needs. Nurses adopting the spiritually empathetic approach recognised that a pragmatic approach might not fully address the spiritual needs of a person and that the spiritual aspect of care was distinct from (but overlapped with) religion.

Many participants spoke of the spiritually empathetic approach in terms of an 'unspoken' acknowledgement and recognition of a spiritual connection with the service users and other like-minded colleagues and described it as a sense of 'knowing'. In the context of spirituality in nursing practice it has been suggested (e.g. Swinton, 2014; Ali et al, 2018) that there are two forms of knowledge: 'nomothetic' and 'idiographic'. 'Nomothetic' knowledge is akin to knowledge in a 'scientific' (narrowly defined sense) - factual and true, it can be replicated, and is falsifiable and generalisable. This is the type of knowledge taught in nurse training and favoured by the nurses in this study who preferred a pragmatic approach. 'Idiographic' knowledge, however, recognises experiences which may only occur once and are unique to that person at that time and in that place, but are no less significant or factual even if the knowing may not be generalisable or replicable. This type of knowledge or understanding can be more related to the participants' personal understandings which were developed from all the influences they experienced in their pre-nursing life and in their personal lives. This 'idiographic' sense of knowledge may then be translated into how the spiritually empathetic nurse approached spiritual needs of service users. This is described by many of the participants in this study in their use of terms like 'light in their eyes' and references to connecting with a person's 'spirit' or 'spirit loss'. It has something in common with concepts of empathy and person-centred care (Kitwood, 1997). Findings from this study support the importance of nurse training which develop the nurse as a person who can relate to service users with compassionate motivation as one human being to another and not merely as a technical expert (Ali et al, 2018). The concept of spiritually competent practice in healthcare (Wattis et al, 2017) recognises both these aspects and the influences of the work environment in facilitating or obstructing good quality spiritual care. This was evidenced in the present study by the way some nurses found the teams they worked with to be supportive of approaching spiritual issues whilst other teams were dismissive. Whilst the

This article is protected by copyright. All rights reserved. 
identification of spiritual competencies for nurses (e.g. van Leeuwen et al 2004) draws welcome attention to this important aspect of care provision, findings from this study highlight the need to humanise approaches to care and to avoid focus on a 'mechanical' approach to nursing encouraged by the standardised assessments described by participants.

\section{Conclusion}

Mental health nurses participating in this study recognised the importance of attending to spiritual needs as part of holistic person-centred care. Findings support previous work highlighting difficulties faced by nurses specific to the field of mental health nursing such as distinguishing spiritual experience and need from potential symptoms of mental ill health. Issues relating both to professional education and the different circumstances within which mental health nurses worked were also highlighted as professional influences on how nurses approached spiritual issues in practice. The distinct pragmatic and spiritually empathetic approaches overlapped in practice though some nurses favoured one more than another. In some ways this reflects the overlap between concepts of religion and spirituality. If a person's spiritual needs are met through religious practice then facilitating this by visits to a prayer room or involving co-religionists is a pragmatic response, especially since religious practice can be beneficial to mental health (Koenig, 2013). However, there is a more individual need, related to a person's sense of hope, meaning and purpose in life for which a spiritually empathetic approach is more useful. The fear of 'getting it wrong' especially in a multi-cultural secular society was pervasive and needs to be addressed.

Findings from this study have clear pragmatic implications for nursing practice and education. Mental health nurses (with help when necessary from colleagues in other disciplines) need to be able to distinguish psychopathology from culturally or subculturally normal religious/spiritual experience. They need to know enough about different religions and different ways of experiencing and expressing spirituality to overcome their fears of "getting it wrong" if only by asking, with permission, for expert advice from chaplaincy services or service users' co-religionists. To sustain a positive approach to spiritual care they need to develop not only this knowledge but the personal capacity to respond in a spiritually empathetic way. They need education, continuing professional development, and supportive team and management cultures if they are to do their best for service users' spiritual needs. Collaborative work in the context of spirituality and adult mental health nursing with agencies like the NMC and RCN should be explored to develop and provide workable, consistent education and guidance for nurses working with people with complex mental health needs. There are opportunities for education about the spiritually empathetic approach alongside teaching listening skills and principles of person-centred care. For example, the first author has successfully developed and implemented an education workshop for pre-registration nurses encouraging students to explore spirituality and spiritual care within the context of mental health nursing (see Elliott, 2017). The workshop begins by asking students to develop an agreed and workable

This article is protected by copyright. All rights reserved. 
definition of spirituality to highlight the difficulties and encourage them to be aware of other perspectives. Students are then asked to consider what good spiritual care might look like before exploring how this might be achieved in difficult and restrictive environments. Consistent approaches to including spirituality in nurse education are lacking (Snowden \& Ali, 2017) and there is a need for clarity in policy documents to ensure that education in this area is consistent and not understood as a matter of choice.

In keeping with the qualitative approach taken, this was a relatively small study of nurses in one organisation. It is not appropriate to make claims as to the generalisability of findings, but we do suggest that findings may well be transferable to other comparable mental health nursing settings. This study adds an in-depth understanding from the mental health nurse perspective of how current mental health nurses understand and try to address spiritual need in service users and, supported by the rapidly developing literature in this field, suggests how we could improve education and support for nurses in this area.

\section{References}

Ali, G., Snowden, M., and Wattis J. (2018). Spirituality in Nursing Education: Knowledge and Practice gaps. International Journal of Multidisciplinary Comparative Studies. 5, 27-49

Ashmore, R. \& Banks, D. (2002). Self-disclosure in adult and mental health nursing. Nurse Education Today, 11(3), 48-57. doi: 10.1054/nedt.2000.0507.

Barker, P. (2004). Psychiatric and Mental Health Nursing: The craft of caring (2 ${ }^{\text {nd }}$ ed.). London: Hodder Arnold.

Bregman, L. (2014). The Ecology of Spirituality. Waco: Baylor University Press.

Brooks, J., McCluskey, S., Turley, E. and King, N. (2015). The Utility of Template analysis in Qualitative Psychology Research. Qualitative Research in Psychology 12, 202-222.

Dwyer, S. C., Buckle, J. L. (2009) The space Between: On Being an Insider-Outsider in Qualitative Research. International Journal of Qualitative Methods 8(1)

Elliott, R. (2011). Spirituality, mental health nursing and assessment. Journal of Community Nursing, 25, 3.

Elliott, R. (2017). An Exploration of Mental Health Nurses' Understanding of the Spiritual Needs of Service Users. Doctoral thesis, University of Huddersfield.

This article is protected by copyright. All rights reserved. 
King, N., Bravington, A., Brooks, J., Melvin, J., and Wilde, D. (2017). "Go Make Your Face Known": Collaborative Working through the Lens of Personal Relationships. International Journal of Integrated Care, 17, 1-11.

King, N., and Brooks, J.M. (2017). Template Analysis for Business and Management Students. London: Sage.

Kitwood, T. (1997). Dementia reconsidered: The person comes first. Berkshire, UK. Open University Press.

Koenig H. G. (2013). Spirituality in Patient Care: Why, How, When, and What (3 ${ }^{\text {rd }}$ ed.). Connecticut: Templeton Foundation Press.

Koslander, T. and Arvidsson B. (2006). Patients' conceptions of how the spiritual dimension is addressed in mental health care: a qualitative study. Journal of Advanced Nursing, 57, 597-604.

McBrien, B. (2006). A concept analysis of spirituality. British Journal of nursing, 15, 42-45.

McSherry, W. (2011). RCN spirituality survey 2010: A report by the Royal College of Nursing on members' views on spirituality and spiritual care in nursing practice. Retrieved from https://www2.rcn.org.uk/data/assets/pdffile/0008/393155/survey003861.pdf

Mc Sherry, W. and Jamieson, S. (2011). An online survey of nurses' perceptions of spirituality and spiritual care. Journal of Clinical Nursing, 20, 1757-176

Mitchell, S. and Roberts, G. (2009). Psychosis. Cited in Cook, C. C. H., Powell, A. and Sims, A. (2009). Spirituality and Psychiatry. London. Blackwell.

Nursing and Midwifery Council (NMC). (2014). NMC Standards of competence required by all nurses to work in the UK. Retrieved from http://www.searchrecruitment.jobs/admin/wgrane_pliki/file-new-nmc-standards-ofcompetence-required-by-nmc\%5b108\%5d.pdf Narayanasamy, A. (1999). A review of spirituality as applied to nursing. International Journal of Nursing, 36, 117-125.

This article is protected by copyright. All rights reserved. 
Narayanasamy, A. and Owens J. (2001). A critical incident study of nurses' responses to the spiritual needs of their patients. Journal of Advanced Nursing, 33, 446-455.

Pesut, B. (2008). Conceptualising spirituality and religion for healthcare. Journal of clinical nursing, 17, 2803-2810.

Rogers, M. and Wattis, J. (2014). Spirituality in nursing practice. Nursing Standard. 29(39), 51-57.

Snowdon, M., and Ali, G. (2017) How can spirituality be integrated in undergraduate and postgraduate education. In Wattis, J., Curren S., and Rogers, M. (2017). Spiritually Competent Practice in Health Care. CRS Press, London.

Swinton, J. (2001). Spirituality and Mental Health: Rediscovering a forgotten dimension. London: Jessica Kingsley Publishers.

Swinton, J. and Pattinson, S. (2010). Moving beyond clarity: Towards a thin, vague and useful understanding of spirituality in nursing care. Nursing Philosophy. 11, 226-237.

Swinton, J. (2014). Healthcare spirituality: A Question of knowledge. In Cobb, M., Puchalski, C. M. and Rumbold, B. (eds.). Oxford Textbook of Spirituality in Healthcare. Oxford. Oxford University Press.

Thomas, D.R. (2017). Feedback from research participants: are member checks useful in qualitative research? Qualitative Research in Psychology, 14(1), 23-41.

This article is protected by copyright. All rights reserved. 
Tong A, Sainsbury P, Craig J. Consolidated criteria for reporting qualitative research (COREQ): a 32-item checklist for interviews and focus groups. International Journal for Quality in Health Care. 2007. Volume 19, Number 6: pp. 349 - 357

Van Leeuen, R. and Cusveller, B. (2004) Nursing competencies for spiritual care. Journal of Advanced Nursing 48, 234-246.

Waddington, K. and Fletcher, C. (2005). Gossip and emotion in nursing and health-care organisations. Journal of Health Organization and Management, 19, 378-394

Wattis, J., Curren S., and Rogers, M. (2017). Spiritually Competent Practice in Health Care. CRS Press, London.

Weber, S. R. and Pargament, K. I. (2014). The role of religion and spirituality in mental health. Current Opinion in Psychiatry: 44, 358-36

Yardley, L. (2000). Dilemmas in qualitative health research, Psychology and Health, 15(2), 215-228.

This article is protected by copyright. All rights reserved. 
Table 1. Participant details and interview length

\begin{tabular}{|c|c|c|c|c|c|}
\hline $\begin{array}{l}\text { Number of } \\
\text { interviews }\end{array}$ & $\begin{array}{l}\text { Participant } \\
\text { pseudonym }\end{array}$ & Staff Role & Gender & $\begin{array}{l}\text { Approx. } \\
\text { age: e.g. } 30 \\
\text { 's }\end{array}$ & $\begin{array}{l}\text { Approx. } \\
\text { Length of } \\
\text { Interview in } \\
\text { mins: }\end{array}$ \\
\hline 1 & Ann & CPN Insight & $\mathrm{F}$ & 40 's & 45 \\
\hline 2 & Ben & $\begin{array}{l}\text { CPN Adult } \\
\text { services }\end{array}$ & $M$ & 40 's & 45 \\
\hline 3 & Chris & $\begin{array}{l}\text { CPN community } \\
\text { treatment }\end{array}$ & $M$ & 40 's & 40 \\
\hline 4 & Dawn & $\begin{array}{l}\text { Forensic Female } \\
\text { inpatient }\end{array}$ & $F$ & 20 's & 36 \\
\hline 5 & Brendan & $\begin{array}{l}\text { Substance } \\
\text { misuse specialist }\end{array}$ & $M$ & 60 's & 55 \\
\hline 6 & Freya & CPN Adult & $\mathrm{F}$ & 20 's & 66 \\
\hline 7 & Harry & $\begin{array}{l}\text { CPN Assertive } \\
\text { outreach }\end{array}$ & $M$ & 40 's & 57 \\
\hline 8 & Isabel & $\begin{array}{l}\text { Forensic Male } \\
\text { inpatient }\end{array}$ & $F$ & 30 's & 62 \\
\hline 9 & Joe & $\begin{array}{l}\text { Crisis/ Home } \\
\text { treatment team }\end{array}$ & $M$ & 60 's & 63 \\
\hline 10 & Emma & Acute inpatient & $\mathrm{F}$ & 50 's & 65 \\
\hline 11 & Kate & $\begin{array}{l}\text { Therapy } \\
\text { services }\end{array}$ & $F$ & 40 's & 61 \\
\hline 12 & Lisa & $\begin{array}{l}\text { Crisis } \\
\text { Resolution }\end{array}$ & $F$ & 40 's & 48 \\
\hline 13 & Mary & $\begin{array}{l}\text { CPN insight } \\
\text { team }\end{array}$ & $\mathrm{F}$ & 50 's & 61 \\
\hline 14 & Nick & $\begin{array}{l}\text { A and } E \text { liaison } \\
\text { team }\end{array}$ & $\mathrm{M}$ & 50 's & 49 \\
\hline 15 & Olwynn & $\begin{array}{l}\text { Dual diagnosis } \\
(\mathrm{LD} / \mathrm{MH})\end{array}$ & $\mathrm{F}$ & 40 's & 52 \\
\hline 16 & Paul & Forensic Rehab & $M$ & 30 's & 57 \\
\hline 17 & Rachael & CPN Adult & $\mathrm{F}$ & 40 's & 86 \\
\hline
\end{tabular}

This article is protected by copyright. All rights reserved. 
Figure 1: coding template developed through analysis (top level themes and first level subthemes)

1. Role of spirituality - personal perspectives

1.1 Influences growing up

1.2 Intellectual understanding and models of spirituality

1.3 Understandings as individual and personal

1.4 Alternatives to 'spirituality' ('conscious evolution')

1.5 Connectivity and a sense of connection

2. Professional understandings of spiritualty

2.1 Nurse education

2.2 Role of the team

3. Nursing spiritually

3.1 Influences on stance towards patients

3.2 Assessment of spiritual need

3.3 Reconciling individual needs with service requirements

3.4 Impact of specific treatments

3.5 Mental health act and impact of restrictions

4. Permeating anxiety (Integrative)

4.1 Anxieties around term 'spirituality'

4.2 Impact on professional standing

4.3 Professional concerns in relation to service users

This article is protected by copyright. All rights reserved. 